\title{
Occupational stress and the risk of turnover: a large prospective cohort study of employees in Japan
}

\author{
Yuko Kachi ${ }^{1 *}$ (D), Akiomi Inoue ${ }^{1}$, Hisashi Eguchi ${ }^{1}$, Norito Kawakami ${ }^{2}$, Akihito Shimazu ${ }^{3}$ and Akizumi Tsutsumi ${ }^{1}$
}

\begin{abstract}
Background: Although several studies have examined the association between occupational stress and turnover, these studies relied on cross-sectional designs, subjects' self-report, healthcare workforce, or small sample sizes. This study aimed to confirm whether occupational stress increases the risk of turnover in a large-scale prospective cohort study using actual turnover data from company records.

Methods: The participants were 3892 male and 5765 female employees aged 20-49years in a financial service company. We followed them from October 2012 until April 1, 2016 and used company records to identify employees who resigned. We identified employees with high and low stress using the Brief Job Stress Questionnaire. Hazard ratios for turnover in high-stress employees were estimated using Cox proportional hazards models, and population attributable risks were calculated separately for men and women.

Results: During 11,475,862 person-days, 122 men and 760 women resigned. After adjustment for age, length of service, job type, and position, the hazard ratios (95\% confidence intervals) for turnover in high-stress employees were 2.86 (1.74-4.68) for men and $1.52(1.29-1.78)$ for women. The corresponding population attributable risks for high stress were $8.2 \%$ for men and $8.3 \%$ for women. The component scores, i.e., job stressors, psychological/ physical stress response, workplace social support, and job strain (the combination of high job demands and low job control) were also significantly associated with turnover $(p<0.05)$.
\end{abstract}

Conclusions: Occupational stress increases the risk of actual turnover. Measures to prevent occupational stress may be useful to prevent employee turnover.

Keywords: Occupational stress, Turnover, Workers, Administrative data

\section{Background}

Employee turnover is a serious issue faced by many organizations worldwide. Not only is turnover costly in terms of recruiting and training new employees [1], but it can also be costly in terms of reduction in profits through reduced team performance and service levels [2-4]. Preventing turnover is a critical management issue. In some cases, turnover is also costly for workers, as they give up career or interpersonal connections at their previous place of employment [5].

Several studies have reported that occupational stress increases the risk of turnover. However, most studies did

\footnotetext{
*Correspondence: kachi@med.kitasato-u.ac.jp

'Department of Public Health, Kitasato University School of Medicine,

Sagamihara, Japan

Full list of author information is available at the end of the article
}

not investigate actual turnover, but instead addressed turnover intentions [6]. Further, even studies that tracked actual turnover [7-17] relied on subjects' recalled self-report $[8-11,13,14,17]$, not by administrative data, which limit the reliability of the data obtained. In addition, more than half of these studies that tracked actual turnover targeted healthcare workers [11-16], whose turnover rates are notoriously high due to its workforce shortage in many developed countries [6]. Further studies in the sector other than health care are needed. Finally, their sample size was comparatively small (less than 1000) $[8,9,11-14,16]$.

In Japan, the turnover rate has been comparatively low due to unique labor market characteristics $[18,19]$. Japan has relied on life-time employment for a long time 
until 1990s, and then rapidly changed into a contractbased labor market after an economic recession, while labor market mobility remained less flexible. Thus, Japanese workers, particularly male permanent workers with a breadwinner role, tend not to leave the company unless for some extraordinary reason [20]. We aimed to investigate the association between occupational stress and actual turnover via a large-scale prospective cohort study. Towards this goal, we used actual turnover data from the human resources records of employees in a company.

\section{Methods}

\section{Study design and setting}

We conducted a prospective cohort study using human resources records of employees in a financial services company listed on the major stock exchange market. This company conducts a stress check examination annually to maintain and improve employees' health and safety since 2010 .

\section{Participants}

The participants were male and female employees aged $20-49$ years in a financial service company. Of the 16 , 086 employees eligible for the stress check examination (Fig. 1), 13,792 employees completed the BJSQ between October 2012 and November 2012, yielding a response rate of $85.7 \%$. At baseline, we excluded 4049 employees aged 50 and older because they might leave due to (early) retirement during follow-up. We also excluded 70 employees who had a disease history according to past sick pay records (mental disorder, musculoskeletal disorder, cardiovascular diseases, and cerebrovascular diseases) because they might leave due to relapse. Further, we excluded 2 employees with missing gender data, and 14 employees with unknown job type. Thus, a total of 9657 employees (3892 men, 5765 women; aged 2049 years) were followed until April 1, 2016. The company provided anonymous data. Informed consent was obtained from participants using the opt-out method.

\section{Variables}

\section{Outcome}

We identified the employees' turnover date using the human resources records of employees in a company. Generally, employee turnover refers to the voluntary or involuntary departure of employees from their organizations [21]. Voluntary turnover is initiated by the employee's own ambitions or dissatisfaction with work and employment conditions, while involuntary turnover is initiated by the organization (e.g., layoffs and dismissals) [21]. All turnover cases in this study were voluntary.

\section{Stress profile}

We used the construct of occupational stress adopted by The Stress Check Program, which is a new occupational health policy launched by the Japanese government on December 1, 2015. This policy targets the primary prevention of mental health problems by annually monitoring and screening workers with high stress at the workplace and is mandatory for workplaces with 50 or more employees [22].

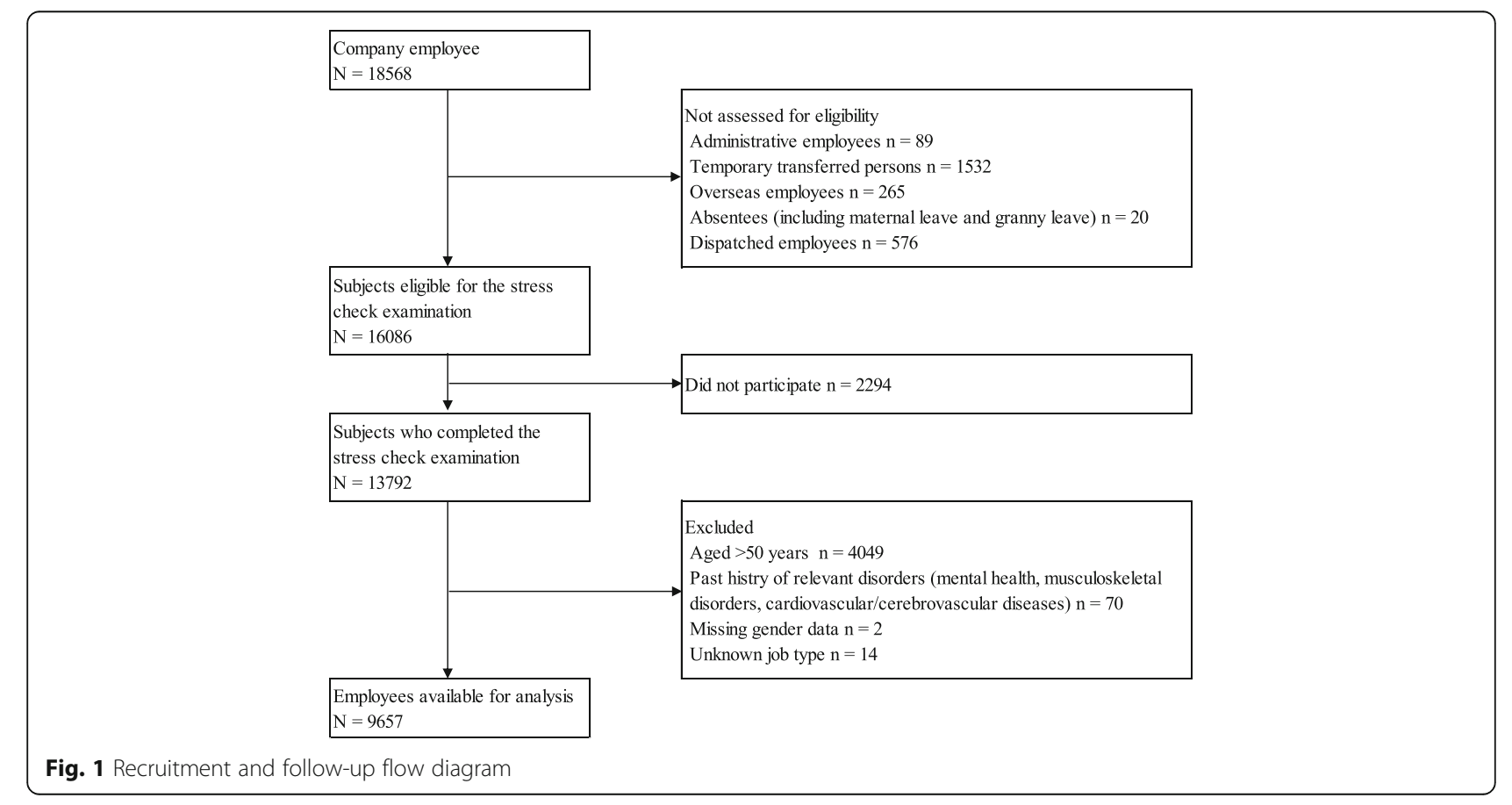


The occupational stress adopted by the Stress Check Program manual include the following three components: (1) job stressors, (2) stress responses, and (3) social supports [23]. Although each workplace can choose any questionnaire to assess these three components, the Stress Check Program manual recommends using the Brief Job Stress Questionnaire (BJSQ). The BJSQ is a 57-item questionnaire that assesses job stressors, stress responses, and social supports as buffering factors based on the NIOSH Job Stress Model [24, 25]. This questionnaire assesses nine aspects of job stressors: quantitative job overload (three items), qualitative job overload (three items), physical demands (one item), job control (three items), skill utilization (one item), interpersonal conflict (three items), poor physical environment (one item), suitable jobs (one item), and meaningfulness of work (one item). The items for job control, skill utilization, suitable jobs, and meaningfulness of work were reversed items. Stress response included the following six aspects: vigor (three items), irritation (three items), fatigue (three items), anxiety (three items), depression (six items), and physical complaints (11 items). Social supports included the following three supports: supervisor support (three items), coworker support (three items), and support from family and friends (three items). This questionnaire also assesses job satisfaction and life satisfaction (one item for each). The answers were provided on a four-point Likert scale $(1=$ Not at all, 2 = Somewhat, $3=$ Moderately so, and 4=Very much so for job stressors; 1 = Almost never, $2=$ Sometimes, $3=$ Often, and $4=$ Almost always for stress responses; and $1=$ Not at all, $2=$ Somewhat, $3=$ Very much, and $4=$ Extremely for social supports). Cronbach's $\alpha$ coefficients were $0.74,0.69,0.94$, and 0.87 for the job demand, job control, stress response, and social support scale, respectively. All BJSQ scales have been proven to have acceptable or high levels of internal consistency reliability and factor-based validity [24].

The Stress Check Program manual proposes criteria for defining high-stress employees based on the BJSQ [22]. The NIOSH Job Stress model postulates job stressors are treated as predictors, stress responses as mediators, and social supports as effect modifiers. However, in our study, according to the instruction of the Stress Check Program, we constructed 'high stress' based on the combination of the three components (job stressors, stress responses, and social support). High stress is defined as the higher level of stress response (criterion A) or having a moderate level of stress response, together with having higher job stressors or lower workplace social support (criterion B). To calculate the score of job stressor, we simply summed the subscale scores of quantitative job overload, qualitative job overload, physical demands, job control, skill utilization, interpersonal conflict, poor physical environment, suitable jobs, and meaningfulness of work. In a similar way, the scores of stress response and social support were calculated. The scores for stress response and the sum of job stressor and social support ranged from 29 to 116 and from 26 to 104, respectively. The cutoff points proposed by the Stress Check Program manual were 77 for the stress response score (criterion A), 76 for the job stressor and social support score, and 63 for the stress response score (criterion B). The criteria have been proven to show good predictive validity for sickness absence [26].

\section{Covariates}

Covariates included gender, age (20-29, 30-39, and 4049 years), length of service ( $0-4,5-9, \geq 10$ years), job type (sales, complaint service, or administrative), and position (staff, manager, or temporary employee).

\section{Statistical analysis}

We analyzed data separately for men and women because of significant difference in job type and position between genders. First, the baseline characteristics were described as numbers (percentage) and were compared between high-stress employees and others using chisquare tests. Second, a Kaplan-Meier curve was generated to compare the cumulative incidences of turnover between high-stress employees and others. Third, Cox's proportional hazard regression analysis was used to investigate the association between stress profiles and onset of turnover. Hazard ratios (HRs) were estimated first after adjusting for age, and then additionally adjusting for length of service, job type, and position. Finally, we estimated the population-attributable risk (PAR) for high stress. The PAR is the fraction of all cases of turnover in a population due to exposure to occupational stress. The PAR percent was calculated as: $(\mathrm{HR}-1) * \mathrm{p} /(1+[\mathrm{HR}-1]$ * $\mathrm{p})$, where $\mathrm{p}$ is the prevalence of high stress in the total population at baseline and HR is the hazard ratio for incident turnover for high stress versus others. We adjusted the PAR estimates for covariates in a similar way to the corresponding Cox models for HRs.

We also conducted three sensitivity analyses. First, we separately tested the stress profiles defined by criteria A and B. Second, we tested the association between occupational stress and onset of turnover using each score for psychological and physical stress response (range 29 to 116), job stressors (17 to 68), and workplace social support (9 to 36) as predictors instead of the stress profiles defined by the Stress Check Program manual. Finally, we evaluated occupational stress by the job demands-control (JDC) model [27] for comparison with previous studies using the JDC model [8, 9, 12]. This model explains occupational stress as an interaction between job demands and job control such that the strongest physiological responses are expected in situations 
involving high job demands and low job control [27]. Job demands and job control were measured by quantitative job overload and job control subscales of the BJSQ, respectively. Each subscale score ranged 3 to 12 . Job strain was defined according to a procedure often used in other studies; individuals in the upper quartile of a job strain ratio (demand score divided by control score) are defined as being exposed [28]. We then tested the association between job strain and onset of turnover. All statistical tests were two-sided, with a 5\% significance level. All analyses were conducted using SAS version 9.3 for Windows (SAS Inc., Cary, NC, USA).

\section{Results}

Table 1 shows the baseline characteristics by stress profiles. High-stress was prevalent in $4.8 \%$ of male employees. Male high-stress employees were older and less likely to be a manager compared to other employees. Meanwhile, high-stress employees was prevalent in $17.5 \%$ of female employees. Female high-stress employees were older, had worked in the company for a longer period, and more likely to work in complaint service sectors.

During 11,475,862 person-days, 122 men and 760 women left the company. The Kaplan-Meier plots showed high-stress employees were more likely to leave the company than others for both men and women (Fig. 2). The progression of turnover was more constant among women than men.
Table 2 shows the results of Cox's proportional hazard regression analysis and PAR for high stress. The ageadjusted HR for incident turnover in high-stress men showed a 4-fold higher risk. After additional adjustment for length of service, job type, and position, the risk for men decreased to 2.86 (95\% confidence interval [CI]: 1.74-4.68). The age-adjusted HR in high-stress women was 1.54 . The HR for women did not change after adjustment of all covariates (HR: 1.52, 95\% CI: 1.29-1.78). PAR for high stress that was calculated with the observed HR of fully-adjusted model was $8.2 \%$ for men and $8.3 \%$ for women

The prevalence of high-stress as defined by criterion A was $3.8 \%$ for men and $15.9 \%$ for women. Meanwhile, its prevalence as defined by criterion B was $2.0 \%$ for men and $6.1 \%$ for women. We found almost the same level of HRs and PARs for criterion A as for high stress defined by a combination of criteria A and B. However, the level of HRs and PARs for criterion $B$ was lower than that for high stress defined by a combination of criteria $\mathrm{A}$ and $\mathrm{B}$ (Table 3).

In the fully-adjusted analyses where each score of psychological and physical stress response, job stressor, and workplace social support was entered separately, the HR of incident turnover was statistically significant for each of these predictors both among men and women. Among men, the HR per 1-point increase of the score was 1.06 (95\% CI: 1.03-1.09) for psychological and physical stress response, 1.03 (95\% CI: 1.02-1.04) for job

Table 1 Baseline characteristics by gender and stress profiles as defined by the Brief Job Stress Questionnaire

\begin{tabular}{|c|c|c|c|c|c|c|c|c|c|c|}
\hline & \multicolumn{5}{|c|}{ Men $(n=3892)$} & \multicolumn{5}{|c|}{ Women $(n=5765)$} \\
\hline & \multicolumn{2}{|c|}{ High stress } & \multicolumn{2}{|c|}{ Others } & \multirow[t]{2}{*}{$p$-value } & \multicolumn{2}{|c|}{ High stress } & \multicolumn{2}{|c|}{ Others } & \multirow[t]{2}{*}{$p$-value } \\
\hline No. of participants & 187 & & 3705 & & & 1007 & & 4758 & & \\
\hline \multicolumn{11}{|l|}{ Age, years } \\
\hline $20-29$ & 25 & $(13.4)$ & 748 & $(20.2)$ & 0.004 & 477 & $(47.4)$ & 2482 & $(52.2)$ & 0.005 \\
\hline $30-39$ & 72 & $(38.5)$ & 1042 & $(28.1)$ & & 291 & $(28.9)$ & 1339 & $(28.1)$ & \\
\hline $40-49$ & 90 & $(48.1)$ & 1915 & $(51.7)$ & & 239 & $(23.7)$ & 937 & $(19.7)$ & \\
\hline \multicolumn{11}{|l|}{ Length of service, years } \\
\hline $0-4$ & 31 & $(16.6)$ & 596 & $(16.1)$ & 0.221 & 375 & $(37.2)$ & 1969 & $(41.4)$ & 0.018 \\
\hline $5-9$ & 36 & $(19.3)$ & 548 & $(14.8)$ & & 316 & (31.4) & 1306 & $(27.5)$ & \\
\hline$\geq 10$ & 120 & $(64.2)$ & 2561 & $(69.1)$ & & 316 & $(31.4)$ & 1483 & $(31.2)$ & \\
\hline \multicolumn{11}{|l|}{ Job type } \\
\hline Sales & 93 & $(49.7)$ & 2130 & $(57.5)$ & 0.097 & 510 & $(50.7)$ & 2644 & (55.6) & $<0.001$ \\
\hline Claims service & 42 & $(22.5)$ & 662 & $(17.9)$ & & 378 & $(37.5)$ & 1251 & (26.3) & \\
\hline Administrative & 52 & $(27.8)$ & 913 & $(24.6)$ & & 119 & $(11.8)$ & 863 & $(18.1)$ & \\
\hline \multicolumn{11}{|l|}{ Position } \\
\hline Staff & 132 & (70.6) & 2231 & $(60.2)$ & $<0.001$ & 922 & $(91.6)$ & 4436 & $(93.2)$ & 0.007 \\
\hline Manager & 39 & $(20.9)$ & 1413 & $(38.1)$ & & 4 & $(0.4)$ & 45 & (1.0) & \\
\hline Temporary employee & 16 & (8.6) & 61 & $(1.7)$ & & 81 & (8.0) & 277 & (5.8) & \\
\hline
\end{tabular}

Values are presented as $\mathrm{n}(\%)$. Variables were compared using chi-square tests 
(a) Men

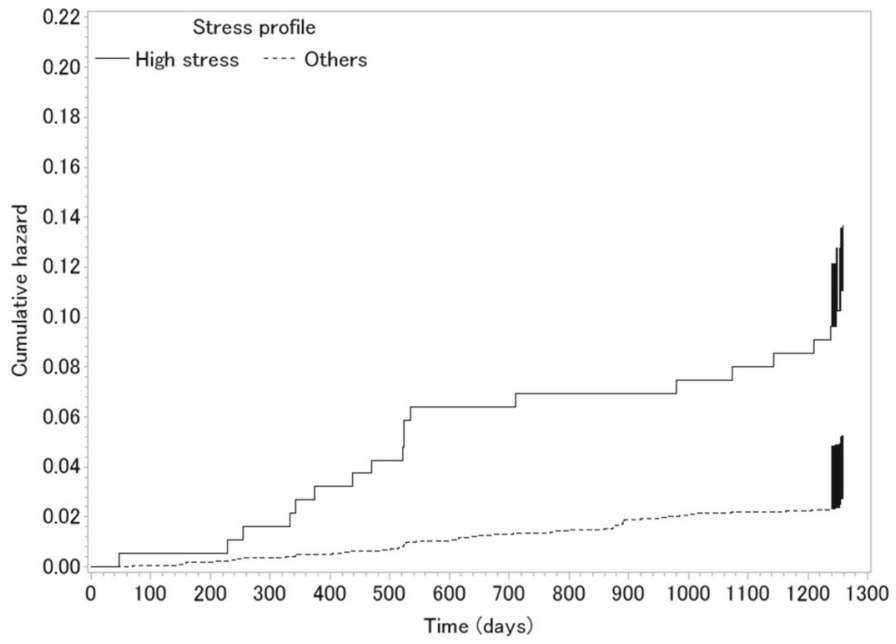

(b) Women

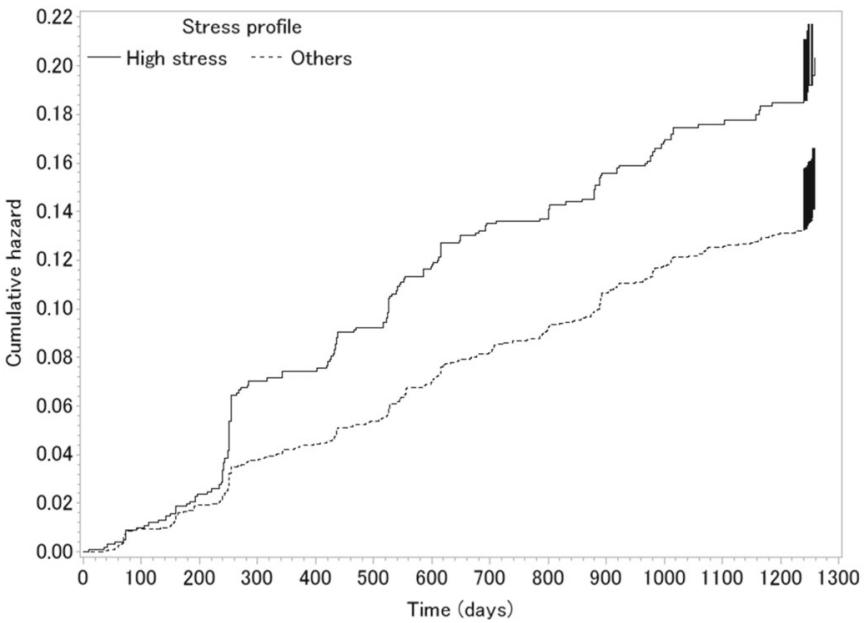

Fig. 2 Cumulative hazard risks for turnover in (a) high-stress men and (b) high-stress women

Table 2 Associations between stress profiles as defined by the Brief Job Stress Questionnaire (BJSQ) and the incidence of turnover

\begin{tabular}{|c|c|c|c|c|c|c|c|c|c|c|}
\hline \multirow{3}{*}{ Men ( $n=3892)$} & \multirow{3}{*}{$\begin{array}{l}\text { Person- } \\
\text { days }\end{array}$} & \multirow[t]{3}{*}{ Cases } & \multirow{3}{*}{$\begin{array}{l}\text { Rate/ } \\
\text { 1000person- } \\
\text { days }\end{array}$} & \multicolumn{6}{|c|}{ HR (95\% Cl) } & \multirow{3}{*}{$\% \mathrm{PAR}^{\mathrm{C}}$} \\
\hline & & & & \multicolumn{2}{|c|}{ Crude model } & \multicolumn{2}{|c|}{ Age-adjusted model ${ }^{a}$} & \multicolumn{2}{|c|}{ Fully-adjusted model $^{b}$} & \\
\hline & & & & & & & & & & \\
\hline High stress & 222,908 & 21 & 0.09 & 4.25 & $(2.65,6.80)^{*}$ & 4.37 & $(2.72,7.00)^{*}$ & 2.86 & $(1.74,4.68)^{*}$ & $8.2 \%$ \\
\hline Others & $4,591,544$ & 101 & 0.02 & 1.00 & & 1.00 & & 1.00 & & \\
\hline \multicolumn{11}{|c|}{ Women $(n=5765)$} \\
\hline High stress & $1,124,502$ & 195 & 0.17 & 1.45 & $(1.24,1.70)^{*}$ & 1.54 & $(1.32,1.81)^{*}$ & 1.52 & $(1.29,1.78)^{*}$ & $8.3 \%$ \\
\hline Others & $5,536,908$ & 665 & 0.12 & 1.00 & & 1.00 & & 1.00 & & \\
\hline
\end{tabular}

HR Hazard ratio; $C l$ confidence interval; PAR Population-attributable risk. ${ }^{*} p<0.05$

${ }^{a}$ Adjusted for age

${ }^{b}$ Adjusted for age, length of service, job type, and position

CPAR was calculated with the observed HR of fully-adjusted model 
Table 3 Associations between stress profiles based on criterion A or B and the incidence of turnover

\begin{tabular}{|c|c|c|c|c|c|c|c|}
\hline & \multicolumn{6}{|c|}{ HR $(95 \% \mathrm{Cl})$} & \multirow[b]{2}{*}{$\%$ PAR } \\
\hline & \multicolumn{2}{|c|}{ Crude model } & \multicolumn{2}{|c|}{ Age-adjusted model $^{a}$} & \multicolumn{2}{|c|}{ Fully-adjusted model $^{b}$} & \\
\hline \multicolumn{8}{|l|}{$\overline{C r i t e r i o n} \mathrm{~A}^{\mathrm{e}}$} \\
\hline \multicolumn{8}{|l|}{ Men $(n=3892)$} \\
\hline High stress & 4.80 & $(2.94,7.83)^{*}$ & 4.94 & $(3.02,8.07)^{*}$ & 3.32 & $(1.99,5.56)^{*}$ & $8.1 \%$ \\
\hline Others & 1.00 & & 1.00 & & 1.00 & & \\
\hline \multicolumn{8}{|c|}{ Women $(n=5765)$} \\
\hline High stress & 1.50 & $(1.27,1.76)^{*}$ & 1.57 & $(1.33,1.84)^{*}$ & 1.54 & $(1.31,1.82)^{*}$ & $7.9 \%$ \\
\hline Others & 1.00 & & 1.00 & & 1.00 & & \\
\hline \multicolumn{8}{|l|}{ Criterion $\mathrm{B}^{\mathrm{e}}$} \\
\hline \multicolumn{8}{|l|}{ Men $(n=3892)$} \\
\hline High stress & 3.13 & $(1.46,6.72)^{*}$ & 3.26 & $(1.52,7.00)^{*}$ & 1.95 & $(0.89,4.26)^{*}$ & $1.9 \%$ \\
\hline Others & 1.00 & & 1.00 & & 1.00 & & \\
\hline \multicolumn{8}{|l|}{ Women $(n=5765)$} \\
\hline High stress & 1.22 & $(0.93,1.58)$ & 1.45 & $(1.11,1.88)^{*}$ & 1.39 & $(1.07,1.80)^{*}$ & $2.3 \%$ \\
\hline Others & 1.00 & & 1.00 & & 1.00 & & \\
\hline
\end{tabular}

HR Hazard ratio; $\mathrm{Cl}$ confidence interval; PAR Population-attributable risk. ${ }^{*} p<0.05$

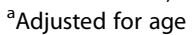

${ }^{\mathrm{b}}$ Adjusted for age, length of service, job type, and position

'PAR was calculated with the observed HR of fully-adjusted model

${ }^{e}$ Criterion $A$ is defined as the highest level of stress response as measured via the Brief Job Stress Questionnaire (cutoff 77) and criterion B is defined as a moderate or higher level of stress response (cutoff 63), along with having the highest job stressors (or lowest social support in the workplace) (cutoff 76), according to the Stress Check Program manual. It should be noted that there is overlap in the distribution of criteria A and B

stressors, and 1.08 (95\% CI: 1.04-1.12) for lack of workplace social support. Among women, the HR per score unit was 1.03 (95\% CI: 1.02-1.05) for psychological and physical stress response, 1.01 (95\% CI: 1.01-1.02) for job stressors, and 1.01 (95\% CI: 1.00-1.02) for lack of workplace social support.

When job strain was entered as a predictor in the fully-adjusted model, the HR of incident turnover was statistically significant for job strain both among men (HR: 1.55, 95\% CI: 1.06-2.27) and women (HR: 1.29, 95\% CI: 1.12-1.50).

\section{Discussion}

This cohort study showed significant prospective associations between occupational stress and actual turnover in a Japanese working population, where the job mobility is markedly less frequent than that in Western countries. Male and female high-stress employees had approximately 3 times higher and 1.5 times higher risk of turnover, respectively, compared with their low-stress counterparts. Although the magnitude of the effect of high stress on turnover was smaller in women than in men, the impact of high stress in this population (i.e., the size of the PAR) was almost similar (8\%) between genders because the high stress was more prevalent in women (17.5\%) than in men (4.8\%).

Similar results from previous studies conducted in China and European countries, including Denmark, the Netherlands, and Sweden, were obtained despite differences in social and cultural contexts. These studies indicated that adverse psychosocial work environment evaluated according to workplace bullying, the JDC model [27], and the effort-reward imbalance model [29] and stress responses such as depression and anxiety were associated with the incidence of turnover [7-17, 30]. We expanded the generalizability of these findings by using administrative outcome data and recruiting a general worker population whose turnover rate was comparatively low.

Our results from supplemental analyses based on the JDC model confirmed that job strain was associated with the incidence of turnover, consistent with a previous study [8]. However, the magnitude of HR for high stress was higher than that for job strain both among men and women. This suggests that the combination of job stressors and stress response may be more predictive of turnover than limited job stressors only.

Our study also illustrated gender differences in the magnitude of the effect of high stress on turnover, and the HR was smaller for women than men. Such gender differences have been found in previous studies [8]. This may be due to the social norms of gender roles, that is, men as breadwinner and women as caregiver. Some women may leave the company due to family roles such as housekeeping and childrearing [31]. Thus, the association between occupational stress and turnover may have been weaker among women than among men. 
Men were less likely to leave the company than women, which might reflect the still prevailing Japanese malebreadwinner model [20]. Turnover rates spiked during the first 2 years then plateaued among men, whereas the progression was constant among women. The different patterns of the turnover may be due to the difference in job types between genders. Most men worked as sales personnel selling insurance, while more women were engaged in the complaint service department of the insurance company. Compared to the complaint service department where the work is more predictable and fixed, sales is more flexible and the job responsibilities are likely to change according to the customers and the insurance products, and the stress level may have changed during the follow-up.

Our study suggested that reducing occupational stress could help prevent turnover. Previous studies suggested that improving the work environment and providing stress management skills to high-stress workers effectively reduce occupational stress [32-34]. Thus, organizations should consider improving the work environment and providing stress management training to prevent turnover [32]. However, unmeasured other factors, probably including management style, career advancement, and pay/benefits [6], should also be considered to prevent turnover.

This study has some limitations. First, our study was based on a convenient sample, which mainly comprised white-collar workers engaged in sales, complaint service, and administration of a financial company. Thus, the generalizability of the results is limited. Second, we lacked data on potential confounders such as working hours and work-life balance. Third, although all turnover cases in this study was voluntary turnover, we lacked data on the reasons for turnover. Despite these limitations, our study had several important strengths, including its large sample size, the use of actual turnover data from company records, and longitudinal design. In addition, our study shows that the criteria for defining high stress set by the Stress Check Program manual have an advantage in that it is simple and practical for identifying individuals at risk of turnover.

\section{Conclusions}

The results of this cohort study indicate that occupational stress is associated with a higher risk of turnover among both male and female Japanese employees. Future studies should replicate this association in other population and examine the effectiveness of reducing occupational stress on turnover reduction among employees.

\section{Abbreviations}

BJSQ: Brief Job Stress Questionnaire; HRs: Hazard ratios; JDC: Job demandscontrol; PAR: Population-attributable risk

Acknowledgements

we thank a financial service company for providing data.

\section{Authors' contributions}

YK designed the study, and wrote the initial draft of the manuscript. AT contributed to data collection and interpretation, and assisted in the preparation of the manuscript. Al, HE, NK, and AS contributed to data interpretation, and critically reviewed the manuscript. All authors read and approved the final manuscript.

\section{Funding}

The present study was supported by the Ministry of Health, Labour and Welfare, Japan [Health and Labour Sciences Research Grants (Research on Occupational Safety and Health) 2015-2017 (Grant Number H27-Rodo-Ippan004) and Industrial Disease Clinical Research Grants 2018 (Grant Number 180701-01)]. The funders had no role in study design, data collection and analysis, decision to publish, or preparation of the manuscript.

\section{Availability of data and materials}

The datasets analyzed during the current study are not publicly available due to privacy concerns and institutional policy.

\section{Ethics approval and consent to participate}

This study was approved by Kitasato University Medical Ethics Organization (No. B15-113). Informed consent was obtained from participants using the opt-out method. Kitasato University Medical Ethics Organization approved the use of opt-out consent.

\section{Consent for publication}

Not applicable.

\section{Competing interests}

The authors declare that they have no competing interests.

\section{Author details}

'Department of Public Health, Kitasato University School of Medicine, Sagamihara, Japan. ${ }^{2}$ Department of Mental Health, Graduate School of Medicine, The University of Tokyo, Tokyo, Japan. ${ }^{3}$ Faculty of Policy Management, Keio University, Fujisawa, Japan.

Received: 27 May 2019 Accepted: 27 January 2020

Published online: 04 February 2020

\section{References}

1. Allen DG, Bryant PC, Vardaman JM. Retaining talent: replacing misconceptions with evidence-based strategies. Acad Manag Perspect. 2010;24(2):48-64.

2. Kacmar KM, Andrews MC, van Rooy DL, Steilberg C, Cerrone S. Sure everyone can be replaced... but at what cost? Turnover as a predictor of unit-level performance. Acad Manag J. 2006;49:133-44.

3. Shaw JD, Gupta N, Delery JE. Alternative conceptualizations of the relationship between voluntary turnover and organizational performance. Acad Manag J. 2005;48:50-68.

4. Batt R. Managing customer services: human resource practices, quit rates, and sales growth. Acad Manag J. 2002:45:587-97.

5. Holtom BC, Mitchell T, Lee T, Eberly M. Turnover and retention research: a glance at the past, a closer review of the present, and a venture into the future. Acad Manag Ann. 2008;2(1):231-74.

6. Hayes $\sqcup$, O'Brien-Pallas L, Duffield C, Shamian J, Buchan J, Hughes F, et al. Nurse turnover: a literature review - an update. Int J Nurs Stud. 2012;49(7):887-905.

7. Clausen T, Hansen JV, Hogh A, Garde AH, Persson R, Conway PM, et al. Exposure to negative acts and risk of turnover: a study of a register-based outcome among employees in three occupational groups. Int Arch Occup Environ Health. 2016;89(8):1269-78.

8. Soderberg M, Harenstam A, Rosengren A, Schioler L. Psychosocial work environment, job mobility and gender differences in turnover behaviour: a prospective study among the Swedish general population. BMC Public Health. 2014;14:605.

9. de Croon EM, Sluiter JK, Blonk RW, Broersen JP, Frings-Dresen MH. Stressful work, psychological job strain, and turnover: a 2-year prospective cohort study of truck drivers. J Appl Psychol. 2004:89(3):442-54.

10. Lund T, Iversen L, Poulsen KB. Work environment factors, health, lifestyle and marital status as predictors of job change and early retirement in physically heavy occupations. Am J Ind Med. 2001;40(2):161-9. 
11. Suzumura M, Fushiki Y, Kobayashi K, Oura A, Suzumura S, Yamashita M, et al. A prospective study of factors associated with risk of turnover among care workers in group homes for elderly individuals with dementia. J Occup Health. 2013;55(6):487-94.

12. Rickard G, Lenthall S, Dollard M, Opie T, Knight S, Dunn S, et al. Organisational intervention to reduce occupational stress and turnover in hospital nurses in the Northern Territory, Australia. Collegian. 2012;19(4):211-21.

13. Cho SH, Lee JY, Mark BA, Yun SC. Turnover of new graduate nurses in their first job using survival analysis. J Nurs Scholarsh. 2012;44(1):63-70.

14. Hogh A, Hoel H, Carneiro IG. Bullying and employee turnover among healthcare workers: a three-wave prospective study. J Nurs Manag. 2011;19(6):742-51.

15. Josephson M, Lindberg P, Voss M, Vingard E. The same factors influence job turnover and long spells of sick leave--a 3-year follow-up of Swedish nurses. Eur J Pub Health. 2008;18(4):380-5.

16. Suzuki E, Itomine I, Kanoya Y, Katsuki T, Horii S, Sato C. Factors affecting rapid turnover of novice nurses in university hospitals. J Occup Health. 2006;48(1):49-61.

17. Wang X, Guo J, Zhang X, Qu Z, Tian D, Ma S. The effects of depression and chronic diseases on the work outcomes of employees: a prospective study in Northwest China. Public Health. 2014;128(8):734-42.

18. OECD. Economic Survey of Japan 2017. http://www.oecd.org/eco/surveys/ economic-survey-japan.htm. Accessed 28 Feb 2019.

19. Cabinet Office. The Japanese youth in comparison with the youth of the world: a summary report of the eighth world youth survey. 2009. https:/www8.cao.go.jp/ youth/english/worldyouth8-e/html/mokuji-e.html. Accessed 27 Feb 2019.

20. Cabinet Office. Annual report on the Japanese economy and public finance 2018. https:/www5.cao.go.jp/keizai3/2018/0803wp-keizai/summary.html. Accessed 27 Feb 2019

21. Campion MA. Meaning and measurement of turnover: comparison of alternative measures and recommendations for research. J Appl Psychol. 1991;76:199-212

22. Ministry of Health, Labour and Welfare, Japan. 2015. http://www.mhlw.go.jp/ bunya/roudoukijun/anzeneisei12/. Accessed 27 Sept 2018.

23. Kawakami N, Tsutsumi A. The stress check program: a new national policy for monitoring and screening psychosocial stress in the workplace in Japan. J Occup Health. 2016;58(1):1-6.

24. Shimomitsu T, Harani T, Nakamura K. In: Kato M, editor. The Final development of the Brief Job Stress Questionnaire mainly used for assessmentof the individuals. The Ministry of Labor sponsored grant for the prevention of workrelated illness. Tokyo: Tokyo Medical University; 2000. p. 126-64.

25. Hurrell JJ Jr, McLaney MA. Exposure to job stress--a new psychometric instrument. Scand J Work Environ Health. 1988;14(Suppl 1):27-8.

26. Tsutsumi A, Shimazu A, Eguchi H, Inoue A, Kawakami N. A Japanese stress check program screening tool predicts employee long-term sickness absence: a prospective study. J Occup Health. 2018;60(1):55-63.

27. Karasek RA. Job demands, job decision latitude, and mental strain: implications for job redesign. Adm Sci Q. 1979;24(2):285-308.

28. Landsbergis PA, Schnall PL, Warren K, Pickering TG, Schwartz JE. Association between ambulatory blood pressure and alternative formulations of job strain. Scand J Work Environ Health. 1994;20:349-63.

29. Siegrist J. Adverse health effects of high-effort/low-reward conditions. J Occup Health Psychol. 1996;1 (1):27-41.

30. Deasy JB, Asanati K, Mansouri M. Pre-placement psychological status and staff retention in a call Centre. Occup Med (Lond). 2016;66(4):305-7.

31. National Institute of Population and Social Security Research. Annual Population and Social Security Surveys. 2015; http://www.ipss.go.jp/site-ad/ index_english/Survey-e.asp. Accessed 27 Feb 2019

32. Imamura $K$, Asai $Y$, Watanabe $K$, Tsutsumi A, Shimazu A, Inoue A, et al. Effect of the National Stress Check Program on mental health among workers in Japan: a 1-year retrospective cohort study. J Occup Health. 2018;60(4):298-306.

33. Strazdins L, D'Souza RM, Clements M, Broom DH, Rodgers B, Berry HL. Could better jobs improve mental health? A prospective study of change in work conditions and mental health in mid-aged adults. J Epidemiol Community Health. 2011;65(6):529-34.

34. Andrews DR, Wan $T$. The importance of mental health to the experience of job strain: an evidence-guided approach to improve retention. J Nurs Manag. 2009;17(3):340-51.

\section{Publisher's Note}

Springer Nature remains neutral with regard to jurisdictional claims in published maps and institutional affiliations.

\section{Ready to submit your research? Choose BMC and benefit from:}

- fast, convenient online submission

- thorough peer review by experienced researchers in your field

- rapid publication on acceptance

- support for research data, including large and complex data types

- gold Open Access which fosters wider collaboration and increased citations

- maximum visibility for your research: over $100 \mathrm{M}$ website views per year

At BMC, research is always in progress.

Learn more biomedcentral.com/submissions 